\title{
Agroecology and the emergence of a post COVID-19 agriculture
}

\author{
Miguel A. Altieri ${ }^{1,2} \cdot$ Clara Ines Nicholls ${ }^{1,2}$
}

Accepted: 12 April 2020 / Published online: 12 May 2020

(c) Springer Nature B.V. 2020

For years agroecologists have warned that industrial agriculture became too narrow ecologically, highly dependent on outside inputs, and extremely vulnerable to insect pests, diseases, climate change and now as demonstrated by the COVID19 pandemic prone to a complete shut down by unforeseen crisis.

Like never before, COVID19 has revealed how closely linked human, animal and ecological health are. As a powerful systemic approach, agroecology reveals that the way we practice agriculture can provide opportunities for improving environmental and human health, but if done wrongly, agriculture can cause major risks to health.

The last pandemics (African swine fever, novel influenza H1N1) were all linked to large scale animal production which creates opportunities for many viruses to mutate and spread. The practices at these industrial operations not only leave animals more susceptible to viral infections, but can sponsor the conditions by which pathogens can evolve to more infectious types. The massive and indiscriminate use of antibiotics and growth promoters in industrial livestock models makes things worst by creating pathogenic strains resistant to such to drugs. Like many viruses, various super bacteria are in line for the next pandemics, for which there are no control products available. The situation is aggravated, as large scale monocultures advance at the expense of natural habitats which can lead to disease emergence. Deforestation led by modern agriculture triggers processes by which previously boxed-in pathogens in natural environments are spilling over into livestock and human communities.

This article is part of the Topical Collection: Agriculture, Food \& Covid-19.

Miguel A. Altieri

agroeco3@berkeley.edu

University of California, Berkeley, CA, USA

2 Centro LatinoAmericano de Investigaciones Agroecologicas (CELIA), Medellín, Colombia
Today three crop species, wheat, rice, and corn provide more than $50 \%$ of the calories consumed globally, comprising a low value diet, which significantly impacts the food security, nutritional status and health particularly of poor and vulnerable people. Many countries are losing their food security as the corporate globalized food system has disrupted the diversified food production systems managed by peasants, As a consequence there is a shift from traditional diverse and rich diets to highly processed, energy dense, micro-nutrient-poor foods. Obesity and diet-related chronic diseases have proliferated.

Large-scale crop monocultures are highly vulnerable to pest, weed and disease epidemics, and rely on injections of about $2.3 \mathrm{bn} \mathrm{kg}$ of pesticides yearly, posing major risks to the general population through toxic residues in the food supply. Many insecticides lead to declines in pollinators and natural enemies of pests that contribute key ecosystem services to agriculture. This loss of biodiversity costs hundreds of billions of dollars annually in crop production and human health.

In most countries restrictions on travel, trade and lockdown of entire cities has constrained the influx of imported foods with devastating consequences on the poor's access to meals. This is problematic in cities with 10 million or more people which need to import 6000 tons of food per day, traveling on average about $1000 \mathrm{~km}$. Food supplies are also impacted in countries dependent on migrant farmworkers who are particularly vulnerable to COVID19 and if they get sick they cannot get to the fields for harvesting and planting. A sharp decline in trucking and air traffic has limited the capacity to move fresh produce long distances, thus getting plentiful supplies to people, many of whom have suddenly lost their income, is a major challenge. Paradoxically food is being dumped as demand from closed restaurants, schools, stadiums, theme parks and cruise ships has plummeted.

Clearly COVID19 has revealed the socio-ecological fragility of current industrial-globalized food systems and the effects on farming and food supply chains raises concerns about widespread food shortages and price spikes. A 
transition to more socially just, ecologically resilient, localized food systems is urgently needed.

Agroecology depicts a different way forward by providing the principles on how to design and manage agricultural systems best able to withstand future crises-whether pest outbreaks, pandemics, climate disruptions, or financial meltdowns. Agroecology offers the best agricultural system able to cope with future challenges by exhibiting high levels of diversity and resilience while delivering reasonable yields and ecosystem services. Agroecology promotes the restoration of the landscapes in which farming systems are embedded, which enriches the ecological matrix creating "ecological firebreaks" that may help contain pathogens from ecological release.

Evidence shows that agroecology restores the production capacities of small scale farmers, by suppressing pests and weeds and enhancing soil fertility in ecological ways. By producing stable crop yields with low external inputs, biodiverse farms generate income and dietary diversity thus improving smallholders livelihoods. The amplification of agroecology is key for the food sovereignty of most communities, as small farmers who control only $30 \%$ of the global arable land, produce between 50 and $70 \%$ of the food consumed in most countries.

Agroecology also promotes alternative livestock production systems such as silvopastoral systems, which ensure healthy animal production, in addition, restore landscapes and are less conducive to promoting epidemics. Antibiotics are not used in these systems, since animals live outdoors and their diet is based on natural foods that come from healthy soils, thus strengthening the immune systems of these animals.

Agroecology can also improve the productivity of urban agriculture thus contributing to local food security and nutrition, especially in underserved communities. Urban food production will expand as more people realize that in time of crisis, access to locally produced food is strategic. Eating nutritious, plant-based foods derived from local organic farms can fortify people's immune systems.

In the face of COVID 19, agroecology is positioning itself as the only agricultural path that can provide rural families with significant socioeconomic and environmental benefits, while feeding the urban masses, equitably and sustainably. Agroecology entails a fundamentally different vision on the way we produce and consume food, while contributing to the creation of equitable food systems. Eating is an ecological and political act, so that when consumers support local farmers, instead of the corporate food chain which is more vulnerable than small farmer food webs, they create socioecological sustainability and resilience.

The key point here is whether the crisis unfolded by COVID19 will provide the impetus to change industrial agriculture for a transition towards agroecologically based food systems. Transformational change in agriculture must be accompanied by a shift from a market economy to a solidarity economics, from fossil fuels to renewable energies, from big corporations to cooperatives, etc. Such new world will be led by social movements aware that a return to the way agriculture was before the pandemics is not an option; instead they will be actively involved in developing local alternatives to consolidate sustainable and healthy agrolandscapes.

Publisher's Note Springer Nature remains neutral with regard to jurisdictional claims in published maps and institutional affiliations.

Miguel A. Altieri studied agronomy at the University of Chile, and graduated with a Ph.D in entomology at the University of Florida. In 1981 he became Professor of agroecology at the University of California, Berkeley. Now Professor Emeritus of Agroecology, he taught for more than three decades courses in agroecology, rural development and urban agriculture at Berkeley as well as in various Universities in Latin America, Japan, China, Italy, Spain and other countries. He is the author of more than 230 scientific papers and author of more than 20 books published in various languages, including the classic: Agroecology-the science of sustainable agriculture.

Clara Ines Nicholls is a Colombian agronomist with a $\mathrm{Ph} . \mathrm{D}$. in Entomology and Biological Control from the University of California Davis. She is a Permanent Lecturer on Sustainable Rural Development in Latin America at the University of California, Berkeley. She also teaches in various universities in Colombia, Brazil, Nicaragua, Argentina, Spain and Italy. She served as the president of the Latin American Scientific Society of Agroecology (SOCLA-www.socla.co) and is co-director of the Centro LatinoAmericano de Investigaciones Agroecologicas (CELIA) She is the author of 4 books (among them Biodiversity and Pest Management in Agroecosystems) and of more than 50 scientific journal papers. 